\title{
Solution to lead quantitation challenge
}

\section{Enea Pagliano ${ }^{1}$}

Published online: 4 October 2019

(C) Crown copyright in right of Canada 2019

The winner of the Lead quantitation challenge (published in volume 411 issue 9) is: Sami T. Tuomivaara, University of California, San Francisco, CA 94107, USA.

The award entitles the winner to select a Springer book of her choice up to a value of $€ 100$,-.

Our Congratulations!

Mass spectrometry has reached a broad diffusion as a diagnostic tool in many branches of life sciences and analytical chemistry. In the field of elemental analysis, inductively coupled plasma mass spectrometry (ICPMS) has become the standard technique for performing quantitation of elements at the ultratrace level. In a typical analysis, the ICPMS response of standard solutions is first acquired and plotted against concentration. Then, the calibration curve is obtained by linear fitting and is used to calculate analyte concentration in the samples. In mass spectrometric analysis, one must bear in mind that the detector responds to the isotopes of an element and not to the element itself. For example, in the case of lead, the analyst can choose to acquire $m / z$ of $204\left({ }^{204} \mathrm{~Pb}\right), 206\left({ }^{206} \mathrm{~Pb}\right), 207\left({ }^{207} \mathrm{~Pb}\right)$, or $208\left({ }^{208} \mathrm{~Pb}\right)$. Usually, quantitation is obtained on $\mathrm{m} / \mathrm{z}, 208$, which corresponds to the most abundant isotope in the mass spectrum of lead (Fig. 1).

In the Lead quantitation challenge [2], we consider a situation where quantitation of lead is performed by two laboratories on a water sample. In both cases, signals corresponding to ${ }^{206} \mathrm{~Pb},{ }^{207} \mathrm{~Pb}$, and ${ }^{208} \mathrm{~Pb}$ were calculated and used for quantitation. Surprisingly, large discrepancies were obtained between and within laboratory

This article is the solution to the Analytical Challenge to be found at https://doi.org/10.1007/s00216-019-01592-w

Enea Pagliano

enea.pagliano@nrc-cnrc.gc.ca; enea.pagliano@outlook.com

1 National Research Council of Canada, 1200 Montreal Road, Ottawa, ON K1A 0R6, Canada when quantitation was performed on the basis of different isotopes.

For the interpretation of this result, we must consider that the abundance of lead isotopes can vary in nature by more than $20 \%$. For a quantitation model that does not take this effect into account, large biases are therefore expected. In this case, a single isotope is not sufficient to represent the element and a comparison between sample and standard cannot be made relying uniquely on a single isotope without information on its abundance in the material.

In this challenge, the data provided [2] were simulated starting from the isotopic compositions listed in Table 1 . For the water sample, the lead isotopic composition was consistent with the average values reported by Millot and Négrel in French groundwater [3]. The two laboratories used primary standard solutions modeled after the isotopic composition of two international standards: the ERMEB400 [4] and the HIPB-1 CRM [5]. As shown in Table 1, the lead isotopic composition for these materials is quite different and such discrepancies must be considered for data analysis.

Laboratory 1 normalized results:

$$
\begin{aligned}
& { }^{206} \mathrm{~Pb}: w(\mathrm{~Pb})_{\mathrm{A}}=4.7 \cdot 0.249 / 0.237=4.9 \mu \mathrm{g} / \mathrm{l} \\
& { }^{207} \mathrm{~Pb}: w(\mathrm{~Pb})_{\mathrm{A}}=5.1 \cdot 0.214 / 0.223=4.9 \mu \mathrm{g} / 1 \\
& { }^{208} \mathrm{~Pb}: w(\mathrm{~Pb})_{\mathrm{A}}=4.9 \cdot 0.524 / 0.525=4.9 \mu \mathrm{g} / 1
\end{aligned}
$$

Laboratory 2 normalized results:

$$
\begin{aligned}
& { }^{206} \mathrm{~Pb}: w(\mathrm{~Pb})_{\mathrm{A}}=4.3 \cdot 0.271 / 0.237=4.9 \mu \mathrm{g} / 1 \\
& { }^{207} \mathrm{~Pb}: w(\mathrm{~Pb})_{\mathrm{A}}=5.4 \cdot 0.204 / 0.223=4.9 \mu \mathrm{g} / 1 \\
& { }^{208} \mathrm{~Pb}: w(\mathrm{~Pb})_{\mathrm{A}}=5.0 \cdot 0.513 / 0.525=4.9 \mu \mathrm{g} / 1
\end{aligned}
$$

When the results are normalized by taking into account the isotopic composition of lead, the biases disappear and a general agreement within and between laboratory is observed.

In mass spectrometry analysis, this correction is mostly overlooked because, for the majority of elements, the differences between isotopic composition of samples and standards are too small to be noticed. However, for metrological 


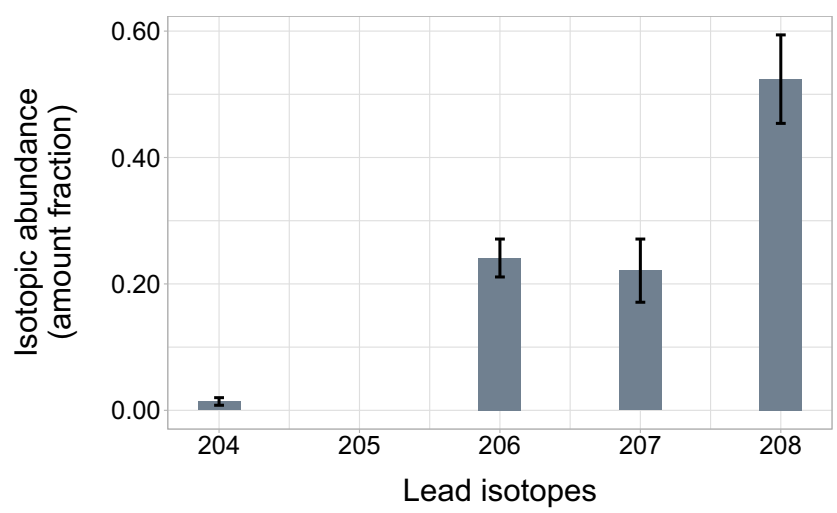

Fig. 1 Isotopic composition of lead: amount fraction of its isotopes and their natural variations in common lead [1]

Table 1 Isotopic abundance (amount fraction) of lead in the sample and in the primary standards employed to model the data for the Lead quantitation challenge [2]

\begin{tabular}{llll}
\hline Isotope & Sample $^{\mathrm{a}}$ & Lab. ${ }^{\mathrm{b}}$ & Lab. ${ }^{\mathrm{c}}$ \\
\hline${ }^{204} \mathrm{~Pb}$ & 0.014 & 0.014 & 0.013 \\
${ }^{206} \mathrm{~Pb}$ & 0.237 & 0.249 & 0.271 \\
${ }^{207} \mathrm{~Pb}$ & 0.223 & 0.214 & 0.204 \\
${ }^{208} \mathrm{~Pb}$ & 0.525 & 0.524 & 0.513 \\
\hline
\end{tabular}

${ }^{\text {a }}$ Similar to a groundwater sampled in France [3]

${ }^{\mathrm{b}}$ Primary standard Lab. 1: from dilution of ERM-EB400 [4]

${ }^{\mathrm{c}}$ Primary standard Lab. 2: from dilution of HIPB-1 CRM [5]

applications, this assumption should be verified in each case.

The exercise proposed for this challenge constitutes a simple scenario where the samples are compared to the primary standards with a linear external calibration curve. Further investigations are needed to evaluate the effects of variable isotopic composition when more complex quantitation models, such as standard addition [6] or isotope dilution [7], are employed.

\section{References}

1. Meija J, Coplen TB, Berglund M, Brand WA, Bièvre PD, Gröning M, Holden NE, Irrgeher J, Loss RD, Walczyk T, Prohaska T. Isotopic compositions of the elements 2013 (IUPAC Technical Report). Pure Appl Chem. 2016;88:293-306. https://doi. org/10.1515/pac-2015-0503.

2. Pagliano E. Lead quantitation challenge. Anal Bioanal Chem. 2019;411:1675-1676. https://doi.org/10.1007/s00216-019-01592-w.

3. Millot R, Négrel P. Lead isotope systematics in groundwater: implications for source tracing in different aquifer types. Procedia Earth Planet Sci. 2015;13:7-10. https://doi.org/10.1016/j.proeps.2015.07. 002.

4. Vogl J, Yim YH, Lee KS, Goenaga-Infante H, Malinovskiy D, Hill S, Ren T, Wang J, Vocke RD, Murphy KE, Nonose N, Rienitz O, Noordmann J. Certification of ERM- EB400, the first matrix reference material for lead isotope amount ratios, and ERMAE142, a lead solution providing a lead isotopic composition at the edge of natural variation. Geostand Geoanalytical Res. 2019;43:2337. https://doi.org/10.1111/ggr.12253.

5. Tong S, Meija J, Zhou L, Methven B, Mester Z, Yang L. Highprecision measurements of the isotopic composition of common lead using MC-ICPMS: comparison of calibration strategies based on full gravimetric isotope mixture and regression models. Anal Chem. 2019;91:4164-4171. https://doi.org/10.1021/acs.analchem. $9 b 00020$.

6. Meija J, Pagliano E, Mester Z. Coordinate swapping in standard addition graphs for analytical chemistry: a simplified path for uncertainty calculation in linear and nonlinear plots. Anal Chem. 2014;86:8563-8567. https://doi.org/10.1021/ac5014749.

7. Pagliano E, Mester Z, Meija J. Reduction of measurement uncertainty by experimental design in high-order (double, triple, and quadruple) isotope dilution mass spectrometry: application to GC-MS measurement of bromide. Anal Bioanal Chem. 2013;405: 2879-2887. https://doi.org/10.1007/s00216-013-6724-5.

Publisher's note Springer Nature remains neutral with regard to jurisdictional claims in published maps and institutional affiliations. 